\title{
Biomechanical analysis of occipitocervical stabilization techniques: emphasis on integrity of osseous structures at the occipital implantation sites
}

\author{
Bryan W. Cunningham, PhD, ${ }^{1}$ Kyle B. Mueller, MD, ${ }^{2}$ Kenneth P. Mullinix, MS, ${ }^{1}$ Xiaolei Sun, MD, ${ }^{3}$ and \\ Faheem A. Sandhu, MD, PhD² \\ ${ }^{1}$ Musculoskeletal Education Center, Department of Orthopaedic Surgery, MedStar Union Memorial Hospital, Baltimore, Maryland; \\ 2Department of Neurosurgery, Georgetown University Medical Center, Washington, DC; and ${ }^{3}$ Department of Orthopaedic \\ Surgery, Tianjin Hospital, Tianjin, China
}

OBJECTIVE The objective of the current study was to quantify and compare the multidirectional flexibility properties of occipital anchor fixation with conventional methods of occipitocervical screw fixation using nondestructive and destructive investigative methods.

METHODS Fourteen cadaveric occipitocervical specimens (Oc-T2) were randomized to reconstruction with occipital anchors or an occipital plate and screws. Using a 6-degree-of-freedom spine simulator with moments of $\pm 2.0 \mathrm{Nm}$, initial multidirectional flexibility analysis of the intact and reconstructed conditions was performed followed by fatigue loading of 25,000 cycles of flexion-extension (x-axis, $\pm 2.0 \mathrm{Nm}$ ), 15,000 cycles of lateral bending (z-axis, $\pm 2.0 \mathrm{Nm}$ ), and 10,000 cycles of axial rotation (y-axis, $\pm 2.0 \mathrm{Nm}$ ). Fluoroscopic images of the implantation sites were obtained before and after fatigue testing and placed on an $\mathrm{x}$-y coordinate system to quantify positional stability of the anchors and screws used for reconstruction and effect, if any, of the fatigue component. Destructive testing included an anterior flexural load to construct failure. Quantification of implant, occipitocervical, and atlantoaxial junction range of motion is reported as absolute values, and peak flexural failure moment in Newton-meters (Nm).

RESULTS Absolute value comparisons between the intact condition and 2 reconstruction groups demonstrated significant reductions in segmental flexion-extension, lateral bending, and axial rotation motion at the $\mathrm{Oc}-\mathrm{C} 1$ and $\mathrm{C} 1-2$ junctions $(p<0.05)$. The average bone mineral density at the midline keel $\left(1.422 \mathrm{~g} / \mathrm{cm}^{3}\right)$ was significantly higher compared with the lateral occipital region at $0.671 \mathrm{~g} / \mathrm{cm}^{3}(p<0.05)$. There were no significant differences between the occipital anchor and plate treatments in terms of angular rotation (degrees; $p=0.150$ ) or $x$-axis displacement (mm; $p=0.572$ ), but there was a statistically significant difference in $y$-axis displacement $(p=0.031)$ based on quantitative analysis of the preand postfatigue fluoroscopic images $(p>0.05)$. Under destructive anterior flexural loading, the occipital anchor group failed at $90 \pm 31 \mathrm{Nm}$, and the occipital plate group failed at $79 \pm 25 \mathrm{Nm}(p>0.05)$.

CONCLUSIONS Both reconstructions reduced flexion-extension, lateral bending, and axial rotation at the occipitocervical and atlantoaxial junctions, as expected. Flexural load to failure did not differ significantly between the 2 treatment groups despite occipital anchors using a compression-fit mechanism to provide fixation in less dense bone. These data suggest that an occipital anchor technique serves as a biomechanically viable clinical alternative to occipital plate fixation.

https://thejns.org/doi/abs/10.3171/2020.1.SPINE191331

KEYWORDS biomechanical properties; occipitocervical fixation; failure mechanisms; cervical

$\mathrm{T}$ HE occipitocervical junction is one of the most mobile regions of the axial skeleton, and the complex neurovascular structures make stabilization and arthrodesis of this region challenging. ${ }^{1,2}$ Since Foerster first described fixation of this junction in 1927 using a fibular strut graft, methods of fixation have evolved from simple onlay of bone graft ${ }^{3,4}$ and posterior wiring ${ }^{5,6}$ to more conventional plate-screw techniques. ${ }^{7,8}$ Although these initial stabilization methods achieved arthrodesis, their need for an extended course of rigid postoperative immobiliza-

ABBREVIATIONS BMD = bone mineral density; $R O M=$ range of motion .

SUBMITTED November 6, 2019. ACCEPTED January 20, 2020.

INCLUDE WHEN CITING Published online April 10, 2020; DOI: 10.3171/2020.1.SPINE191331. 
tion and increased adverse risks have limited their utility. Furthermore, conventional screw-rod techniques use an outside-in fixation strategy and, although biomechanically superior, ${ }^{9-13}$ there is an increased risk of CSF leak or cerebellar hematoma if a more lateral fixation point is used in the suboccipital region. Innovative techniques have focused on achieving more rigid stabilization and simplifying instrumentation in an effort to avoid instrumentationrelated complications. ${ }^{14}$

Occipital anchors represent a new method utilizing intracranial fixation. Employing a compression-fit mechanism to the lateral occipital bone, this method of stabilization may be advantageous in pediatric cases in which the midline bone is thin or when a suboccipital craniectomy has been performed. ${ }^{15,16}$ Additionally, lateral fixation would facilitate better alignment with the caudal cervical instrumentation. This method seeks to circumvent complications of screw fixation to the occiput, which has been demonstrated in patients with rheumatoid arthritis. ${ }^{17}$ However, biomechanical evidence evaluating this method of occipital fixation is lacking.

The current investigation sought to quantify and compare the multidirectional flexibility and fixation properties of an occipital anchor versus conventional midline plate and screw fixation for stabilization of the occipitocervical junction. Using an in vitro human cadaveric model, the nondestructive, 3D load-displacement properties of the occipitocervical junction were quantified followed by destructive flexural loading to assess failure mechanisms at the occipital implantation sites.

\section{Methods}

\section{Specimen Preparation}

Fourteen fresh-frozen human occipitocervical specimens (Oc-T2, age range 66-98 years, mean $77.8 \pm 9.5$ years) were harvested en bloc and used in this investigation. The specimens were obtained from the Maryland State Anatomy Board and immediately packaged in double-thickness plastic bags and stored at $-20^{\circ} \mathrm{C}$. Bone mineral density $\left(\mathrm{BMD} ; \mathrm{g} / \mathrm{cm}^{3}\right)$ scans were conducted using a Lunar Prodigy Scanner 8743 (GE Medical Systems) to calculate BMD within the occipital regions of interest, i.e., the midline and lateral suboccipital squamous regions. Prior to biomechanical analysis, standard anteroposterior and lateral plain radiographs were obtained to exclude specimens with intervertebral disc or osseous pathology. Specimens demonstrating bridging osteophytes or facet joint arthrosis to the point of fusion were excluded from the study. Each specimen underwent manual flexion-extension and lateral bending to ensure that the operative cervical discs and facet joints demonstrated segmental motion. In preparation for biomechanical testing, the cranium and vertebral bodies (C4-7) were secured in rectangular tubing foundations using K-wires and eight 4-point compression screws, respectively. Six acrylic motion-detection marker arrays, each configured with 3 noncollinear infrared-emitting diodes, were affixed to the occiput $(\mathrm{n}=2)$, occipital instrumentation $(\mathrm{n}=$ 1), $\mathrm{C} 1$ and $\mathrm{C} 2$ vertebral bodies $(\mathrm{n}=2)$, and base container $(\mathrm{n}=1$; Fig. 1).

\section{Multidirectional Flexibility and Fatigue Testing}

Three-dimensional flexibility testing was performed utilizing a 6-degree-of-freedom musculoskeletal simulator configured with an optoelectronic motion measurement system (OptoTrak 3020, Northern Digital Inc.) interfaced with a personal computer. The 6-degree-of-freedom gimbal apparatus affixed to the superior vertebral element allowed pure, unconstrained rotational moments about 3 orthogonal axes: axial rotation ( $\pm \mathrm{y}$-axis), flexion-extension ( $\pm \mathrm{x}$-axis), and lateral bending ( $\pm \mathrm{z}$-axis) according to the 3D conceptual framework of Panjabi. ${ }^{18}$ Linear airbearing guide rails and a vertically positioned pneumatic actuator allowed for unconstrained translations $( \pm)$ along the $\mathrm{x}-, \mathrm{y}-$, and $\mathrm{z}$-axes. To determine multidirectional flexibility, nondestructive loading parameters included 6 pure moments: flexion-extension $( \pm 2 \mathrm{Nm})$, lateral bending $( \pm 2$ $\mathrm{Nm})$, and axial rotation $( \pm 2 \mathrm{Nm})$ at an angular displacement rate of $3 \% \mathrm{sec}$. The 3D peak ranges of occipitocervical $(\mathrm{Oc}-\mathrm{C} 1)$ and atlantoaxial $(\mathrm{C} 1-2)$ motions were expressed in Euler angles (degrees). Each test was repeated for 3 loading and unloading cycles, and data from the third cycle were used for analysis. The occipital anchors and plate were implanted prior to intact analysis such that baseline motion of the implants could be conducted without rod attachment.

After analysis of the intact and prefatigue reconstruction conditions, fatigue testing of each specimen was performed under torque control with 25,000 cycles of flexionextension (x-axis, $\pm 2.0 \mathrm{Nm}$ ), 15,000 cycles of lateral bending (z-axis, $\pm 2.0 \mathrm{Nm}$ ), and 10,000 cycles of axial rotation (y-axis, $\pm 2.0 \mathrm{Nm}$ ), followed by postfatigue static analysis. As a final analysis, the specimen was destructively tested in anterior flexion at a constant loading rate of $5 \% \mathrm{sec}$ using an 858 Bionix Test System (MTS Systems Corp.). During destructive testing a circumferential stainless-steel band was applied at $\mathrm{C} 1-2$ to augment fixation of the rod and lateral mass screws to distribute the applied moment directly to the point of occipital fixation. Specimens were copiously moistened using a $0.9 \%$ sodium chloride irrigation solution throughout the testing procedures.

\section{Specimen Reconstruction: Construct Testing Sequence}

Following preparation, the 14 occipitocervical specimens were randomized into two treatment groups: occipital anchor (CASPIAN Occipital Anchor Spinal system, Stryker Spine; $n=7$ ) and occipital plate (CASPIAN Occipital Plate Spinal system, Stryker Spine; $n=7$ ) with multidirectional flexibility testing performed on the intact, prefatigue, and postfatigue reconstruction conditions. Titanium screw-rod instrumentation was implanted from $\mathrm{C} 1-4$ in all specimens to standardize instrumentation across the operative cervical segments. Transpedicular screw fixation was utilized at $\mathrm{Cl} / \mathrm{C} 2$ and lateral mass fixation at $\mathrm{C} 3 / \mathrm{C} 4$. For each reconstruction group, occipital fixation was inserted according to standard clinical technique. For the anchor group, a high-speed Total Performance System Stryker drill (Stryker Corp.) was used to burr two slots in the posterior occiput just superior to the inferior nuchal line. A Kerrison rongeur was then used to clear fragments from the slot edges for final positioning of the anchors. The slots (approximately 20 -mm length $\times$ 

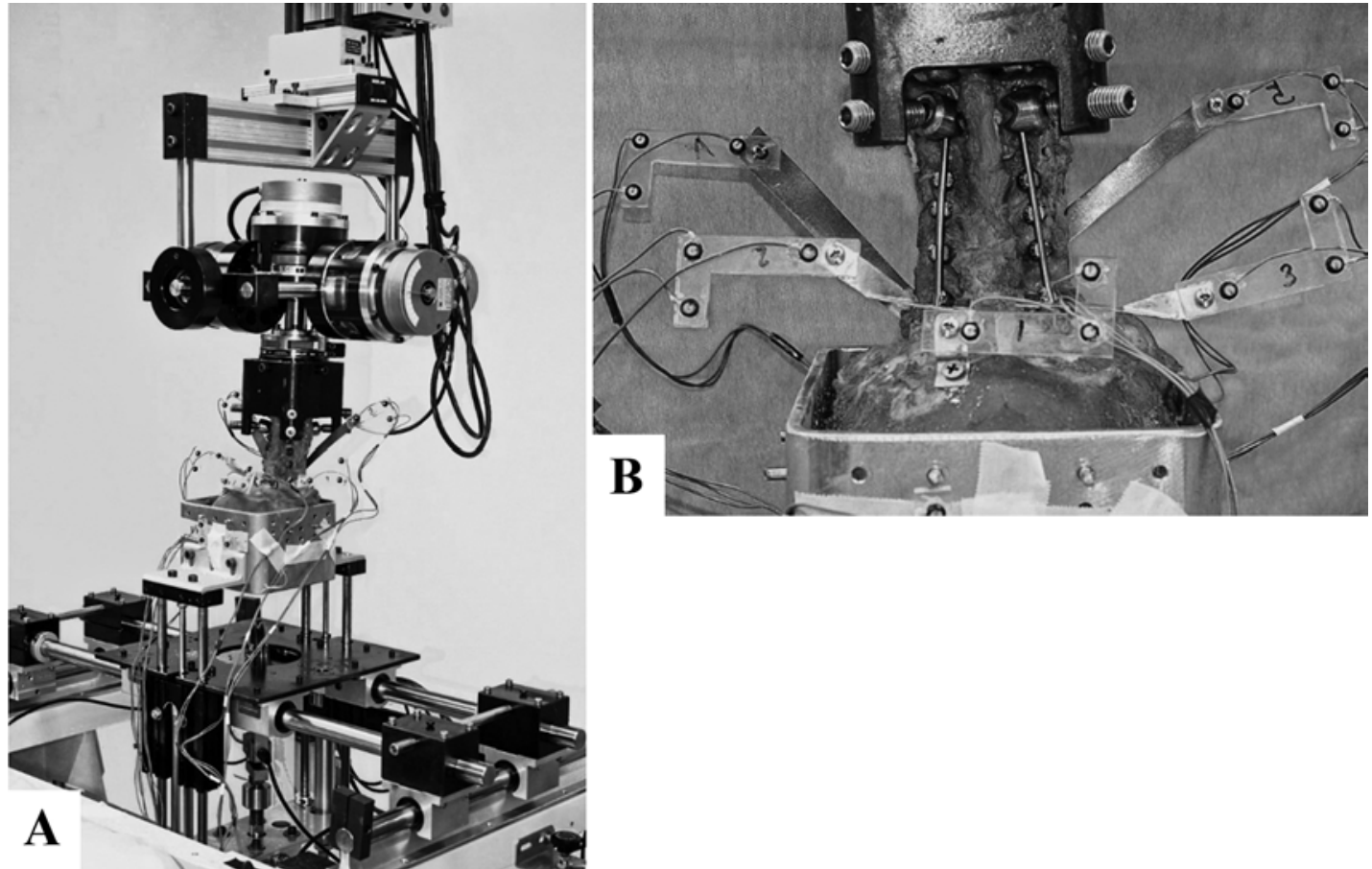

FIG. 1. Representative images of a reconstructed occipital anchor-bolt specimen undergoing nondestructive flexibility testing using a 6 -degree-of-freedom spine simulator $(\mathbf{A})$ with the affixed motion-detection marker arrays configured with noncollinear infraredemitting diodes (B).

10-mm width) were obliquely angled along and through the occipital cortices, which permitted the anchor component to seat firmly against the inner cortex of the cranium. The occipital plate $(50-\mathrm{mm})$ devices were implanted using 3 screws (4.5-mm diameter $\times 15-16-\mathrm{mm}$ length) placed in the midline keel to obtain bicortical purchase. All reconstruction conditions utilized titanium $3.5-\mathrm{mm}$ titanium rods (Fig. 2).

\section{Radiographic Analysis: Implant Positional Stability}

To quantify evidence of implant motion, osseous fractures, or disruption secondary to the implanted devices, high-resolution fluoroscopic images were obtained of the occiput (before and after fatigue testing). These images were imported into the GNU Image Manipulation Program and placed on an $x-y$ orthogonal coordinate system. Positional stability of the anchors and plates (degrees angulation and millimeters translation) was then quantitatively assessed and compared between the pre- and postfatigue conditions (Fig. 3). The angular motion represents the change in angle $(\Delta$; prefatigue - postfatigue) with respect to the $\mathrm{x}$-axis, while the change in linear motion for each of the 4 points (edges of occipital anchors) or 2 points (occipital plate - screw 1 and screw 2) was calculated as follows:

Occipital anchor:

$(\Delta \mathrm{Xmax}=\mathrm{Xmax}$ post $-\mathrm{Xmax}$ pre $)$,

$(\Delta X \min =X \min$ post $-X \min$ pre $)$,

$(\Delta Y \max =\mathrm{Ymax}$ post $-\mathrm{Ymax}$ pre $)$,

$(\Delta Y \min =Y \min$ post $-Y \min$ pre $)$.
The summation of $\Delta \mathrm{Xmax}+\Delta \mathrm{Xmin}$ represents the overall change in linear motion along the $\mathrm{x}$-axis and $\Delta \mathrm{Ymax}$ $+\Delta$ Ymin for the $y$-axis, respectively (post = postfatigue; pre $=$ prefatigue) .

Occipital plate:

$(\Delta$ Xscrew1 $=$ Xscrew1-post - Xscrew1-pre $)$,

$(\Delta$ Xscrew2 $=$ Xscrew2-post - Xscrew2-pre $)$,

$(\Delta$ Yscrew1 $=$ Yscrew1-post - Yscrew1-pre $)$,

$(\Delta$ Yscrew2 $=$ Yscrew2-post - Yscrew2-pre $)$.

The summation of $\Delta X$ screw1 $+\Delta$ Xscrew2 represents the overall change in linear motion along the $\mathrm{X}$-axis and $\Delta$ Yscrew1 $+\Delta$ Yscrew2 for the $y$-axis, respectively (post $=$ postfatigue; pre $=$ prefatigue) .

\section{Data and Statistical Analysis}

BMD $\left(\mathrm{g} / \mathrm{cm}^{3}\right)$ results for the occipital regions of interest-midline keel and lateral squamous region-were averaged and compared between the two treatments using a Student t-test. For the 6 main motions, corresponding to the moments applied, the operative-level segmental range of motion (ROM) was calculated as the sum of the neutral and elastic zones (neutral zone + elastic zone $=$ ROM) and represented the peak total ROM (Euler angle rotation) at the third loading cycle. The expressed degree of rotation (axial rotation $\pm \mathrm{y}$-axis, flexion-extension \pm $\mathrm{x}$-axis, lateral bending $\pm \mathrm{z}$-axis) for multidirectional flexibility analyses was calculated according to the 3D conceptual framework of Panjabi. ${ }^{18}$ The change in range of angular motion was calculated for the occipital plate, right and left anchors, and occipitocervical $(\mathrm{Oc}-\mathrm{C} 1)$ and 



FIG. 2. Representative images of two specimens. External (A) and internal (B) images of the occipital plate with final reconstruction connected with the cervical screws. External (C) and internal (D) images of the occipital anchors with final reconstruction connected with the cervical screws.

atlantoaxial (C1-2) junctions for each specimen and expressed in terms of absolute value (degrees of rotation). Load-to-failure analysis was calculated as the absolute peak moment in Newton-meters $(\mathrm{Nm})$ at construct failure, indicated by a $30 \%$ decrease in load based on the real-time load-displacement trace. Statistical analysis included descriptive analysis (mean \pm standard deviation) and a repeated-measures ANOVA with post hoc Tukey honestly significant difference test for comparison within treatment groups. All data are shown as mean \pm 1 standard deviation and statistical significance was indicated at $\mathrm{p}<0.05$.

\section{Results \\ BMD Analyses}

Comparisons of the BMD values between the midline keel (occipital plate, $\mathrm{n}=7$ ) and lateral occipital squamous (anchor-bolt, $\mathrm{n}=7$ ) regions demonstrated highly significant differences. The lateral regions of fixation utilized by the anchors indicated an average BMD of $0.671 \pm 0.237$ $\mathrm{g} / \mathrm{cm}^{3}$ (range $0.361-1.045 \mathrm{~g} / \mathrm{cm}^{3}$ ), while the middle fixation keel exhibited an average of $1.422 \pm 0.322 \mathrm{~g} / \mathrm{cm}^{3}$ (range $1.010-1.963 \mathrm{~g} / \mathrm{cm}^{3} ; \mathrm{p}<0.0001$, t-test).

\section{Multidirectional Flexibility Testing}

\section{Flexion-Extension ( $\pm \mathrm{x}$-axis)}

For the occipital plate group, flexion-extension loading of the intact specimens exhibited a mean ROM of $5.57^{\circ}$ $\pm 4.84^{\circ}$ at the occipitocervical junction and $5.72^{\circ} \pm 5.41^{\circ}$ at the atlantoaxial joint. The occipital anchor group exhibited a mean ROM of $9.53^{\circ} \pm 2.80^{\circ}$ at the occipitocervical junction and $7.82^{\circ} \pm 3.43^{\circ}$ at the atlantoaxial joint. Comparisons of the ROM values and 2 subsequent reconstruction conditions demonstrated significant reductions in segmental flexion-extension motion at the $\mathrm{Oc}-\mathrm{Cl}$ and C1-2 levels for both pre- and postfatigue $(\mathrm{p}<0.05)$. At the occipital implantation site, there was no difference in implant flexion-extension motion with either the plate or anchors, for the intact compared with the pre- and postfatigue conditions $(p>0.05)$. No significant differences 

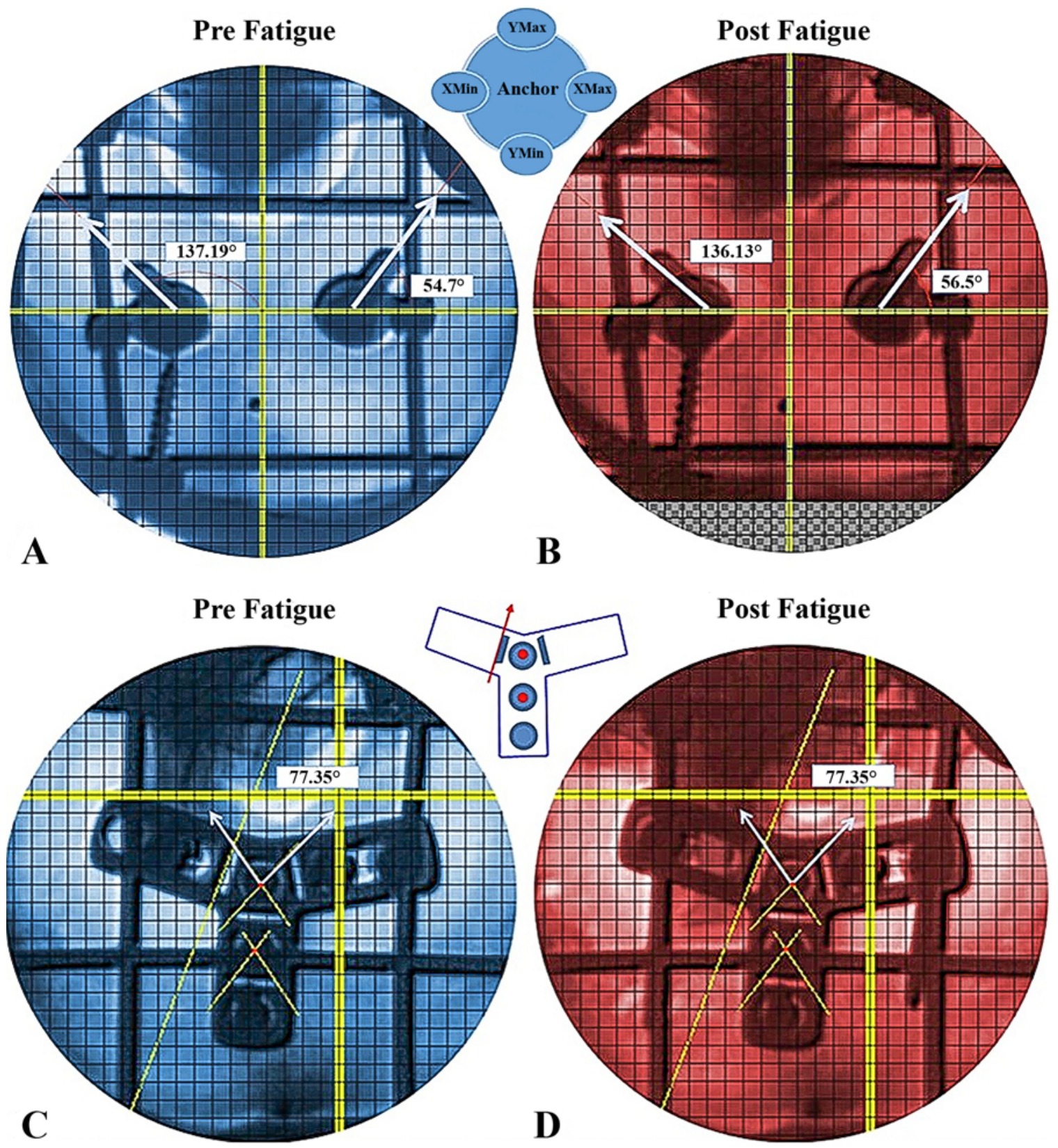

FIG. 3. Pre- and postfatigue fluoroscopic images of the occipital anchor (A and B) and occipital plate (C and D) reconstructions. Using an $x-y$ overlay coordinate system, the positional stability of the anchors and plates was compared.

were observed under this loading condition between reconstructions, and fatigue loading did not significantly alter the kinematics compared to the prefatigue condition at any level for any reconstruction group ( $\mathrm{p}>0.05$; Fig. 4A, Tables 1 and 2).

\section{Lateral Bending ( \pm z-axis)}

For the occipital plate group, lateral bending loading of the intact specimens exhibited a mean ROM of $1.52^{\circ}$ $\pm 1.74^{\circ}$ at the occipitocervical junction and $4.58^{\circ} \pm 3.88^{\circ}$ at the atlantoaxial joint. The occipital anchor group exhibited a mean $\mathrm{ROM}$ of $1.88^{\circ} \pm 1.43^{\circ}$ at the occipitocer- vical junction and $3.24^{\circ} \pm 1.42^{\circ}$ at the atlantoaxial joint. Comparisons of the ROM values and 2 subsequent reconstruction conditions demonstrated significant reductions in segmental lateral bending motion at the C1-2 level for both pre- and postfatigue conditions $(\mathrm{p}<0.05)$. At the occipital implantation site there was a significant difference in implant lateral bending motion, with both the plate and anchors, for the intact compared with the pre- and postfatigue conditions $(p<0.05)$. Fatigue loading did not significantly alter the kinematics compared to the prefatigue condition for the occipital plate or anchors ( $p>0.05$; Fig. 4B, Tables 1 and 2). 
A Occipital Anchor: Flexion-Extension

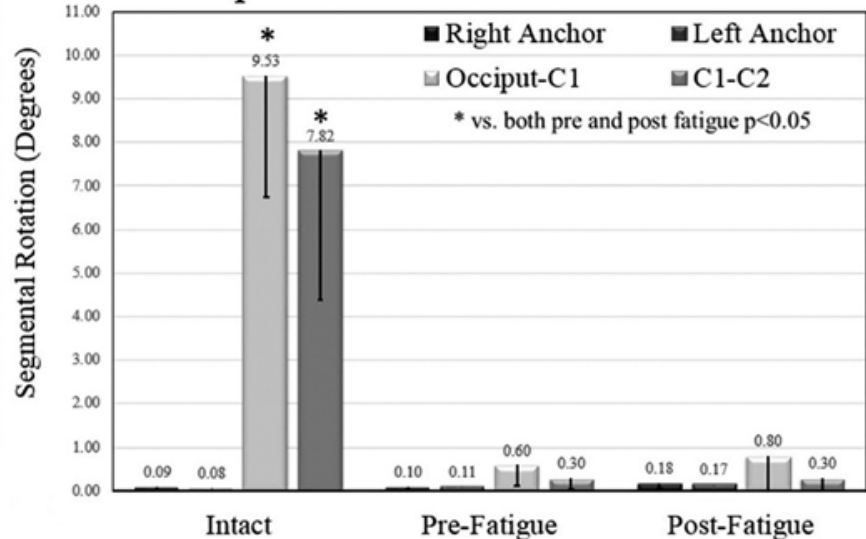

B

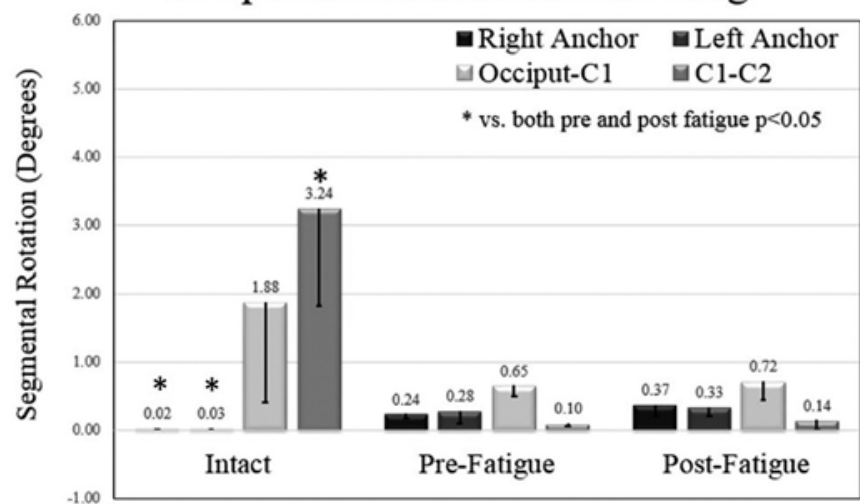

C

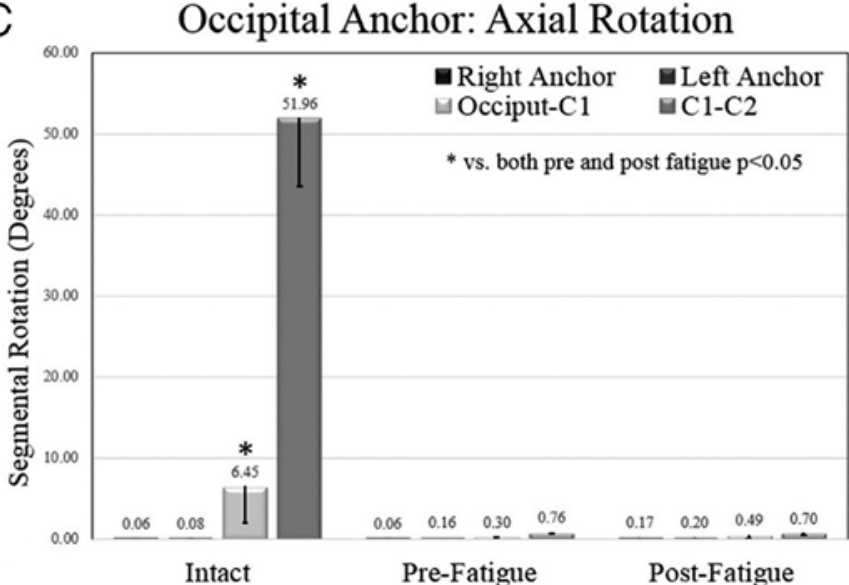

Occipital Plate: Flexion-Extension

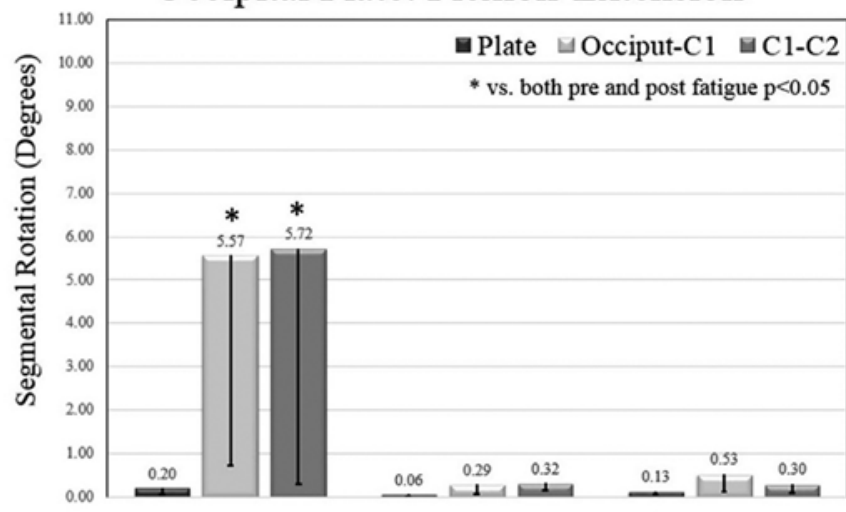

Intact

Post-Fatigue

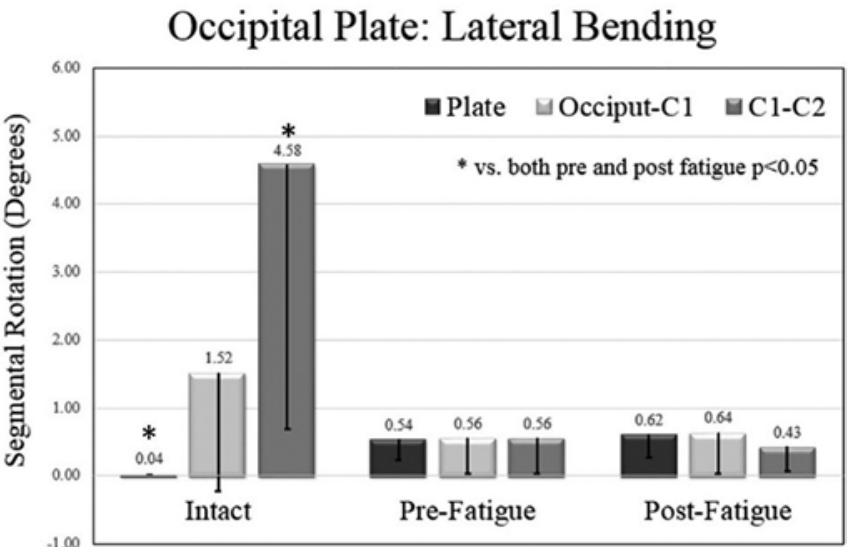

Occipital Plate: Axial Rotation

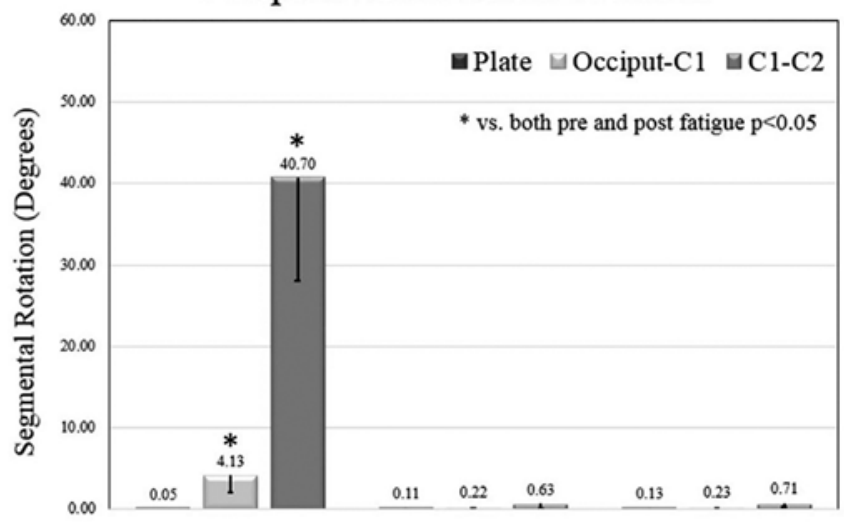

Intact

Pre-Fatigue

Post-Fatigue

FIG. 4. A: Flexion-extension ROM. Comparisons of the intact spine and occipital fixation with either plate-screw or anchor-bolt for pre- and postfatigue reconstruction conditions demonstrated significant reductions in segmental Oc-C1 and C1-2 operativelevel motion $(p<0.05)$. B: Lateral bending ROM. Comparisons of the intact spine and occipital fixation with either plate-screw or anchor-bolt for pre- and postfatigue reconstruction conditions demonstrated significant reductions in segmental Oc-C1 and $\mathrm{C} 1-2$ operative-level motion $(p<0.05)$. C: Axial rotation ROM. Comparisons of the intact spine and occipital fixation with either platescrew or anchor-bolt for pre- and postfatigue reconstruction conditions demonstrated significant reductions in segmental Oc-C1 and $\mathrm{C} 1-2$ operative-level motion $(\mathrm{p}<0.05)$. Bar height represents mean values and error bars minus 1 standard deviation. ${ }^{*} p<$ 0.05 . 
TABLE 1. Multidirectional flexibility data: segmental ROM

\begin{tabular}{|c|c|c|c|c|c|c|c|c|c|c|c|c|}
\hline \multirow[b]{3}{*}{ Loading Mode } & \multicolumn{6}{|c|}{ Occipital Plate-Screw $\left({ }^{\circ}\right)$} & \multicolumn{6}{|c|}{ Occipital Anchor $\left(^{\circ}\right)$} \\
\hline & \multicolumn{2}{|c|}{ Intact } & \multicolumn{2}{|c|}{ Prefatigue } & \multicolumn{2}{|c|}{ Postfatigue } & \multicolumn{2}{|c|}{ Intact } & \multicolumn{2}{|c|}{ Prefatigue } & \multicolumn{2}{|c|}{ Postfatigue } \\
\hline & $\mathrm{Oc}-\mathrm{C1}$ & $\mathrm{C} 1-2$ & $\mathrm{Oc}-\mathrm{C1}$ & C1-2 & $\mathrm{Oc}-\mathrm{C} 1$ & C1-2 & $\mathrm{Oc}-\mathrm{C1}$ & C1-2 & $\mathrm{Oc}-\mathrm{C1}$ & $\mathrm{C} 1-2$ & $\mathrm{Oc}-\mathrm{C1}$ & $\mathrm{C} 1-2$ \\
\hline \multicolumn{13}{|l|}{ Flexion-extension } \\
\hline Mean & 5.57 & 5.72 & 0.29 & 0.32 & 0.53 & 0.30 & 9.53 & 7.82 & 0.60 & 0.30 & 0.80 & 0.30 \\
\hline SD & 4.84 & 5.41 & 0.23 & 0.17 & 0.41 & 0.21 & 2.80 & 3.43 & 0.48 & 0.27 & 0.83 & 0.31 \\
\hline \multicolumn{13}{|l|}{ Lateral bending } \\
\hline Mean & 1.52 & 4.58 & 0.56 & 0.37 & 0.64 & 0.43 & 1.88 & 3.24 & 0.65 & 0.10 & 0.72 & 0.14 \\
\hline SD & 1.74 & 3.88 & 0.53 & 0.23 & 0.61 & 0.35 & 1.43 & 1.42 & 0.16 & 0.05 & 0.29 & 0.13 \\
\hline \multicolumn{13}{|l|}{ Axial rotation } \\
\hline Mean & 4.13 & 40.70 & 0.22 & 0.63 & 0.23 & 0.71 & 6.45 & 52.00 & 0.30 & 0.76 & 0.49 & 0.70 \\
\hline SD & 2.05 & 12.70 & 0.13 & 0.60 & 0.14 & 0.52 & 4.47 & 8.48 & 0.21 & 0.11 & 0.50 & 0.29 \\
\hline
\end{tabular}

\section{Axial Rotation ( \pm y-axis)}

For the occipital plate group, axial rotation loading of the intact specimens exhibited a mean ROM of $4.13^{\circ} \pm$ $2.05^{\circ}$ at the occipitocervical junction and $40.70^{\circ} \pm 12.70^{\circ}$ at the atlantoaxial joint. The occipital anchor group exhibited a mean ROM of $6.45^{\circ} \pm 4.47^{\circ}$ at the occipitocervical junction and $51.96^{\circ} \pm 8.48^{\circ}$ at the atlantoaxial joint. Comparisons of the ROM values and 2 subsequent reconstruction conditions demonstrated significant reductions in segmental axial rotation at the $\mathrm{Oc}-\mathrm{C} 1$ and $\mathrm{C} 1-2$ levels both pre- and postfatigue $(\mathrm{p}<0.05)$. At the site of occipital fixation, there was no difference in implant axial rotation motion, with the plate or anchors, for the intact compared with the pre- and postfatigue conditions ( $\mathrm{p}>$ 0.05). Multidirectional kinematics of the occipitocervical junction demonstrated the most significant changes under axial rotation. No significant differences were observed under this loading condition between reconstructions, and fatigue loading did not significantly alter the kinematics compared to the prefatigue condition at any level for any reconstruction group ( $p>0.05$; Fig. 4C, Tables 1 and 2).

\section{Radiographic Analysis: Implant Positional Stability}

A comparison of the overall change in angular rotation and $\mathrm{x}-\mathrm{y}$ axis displacement for the occipital anchors versus occipital plates showed no significant differences between the occipital anchor and plate treatments in terms of angular rotation (degrees; $\mathrm{p}=0.150$ ) or $\mathrm{x}$-axis displacement $(\mathrm{mm} ; \mathrm{p}=0.572)$ based on quantitative analysis of the preand postfatigue fluoroscopic images $(\mathrm{p}>0.05)$. There was a statistically significant increase in $y$-axis displacement for the anchor treatment ( $\mathrm{p}=0.031$; Fig. 5).

\section{Destructive Testing}

No significant differences were observed among the 2 treatment groups (occipital anchor and occipital plate) under destructive anterior flexural load to failure $(\mathrm{p}>0.05)$. The occipital plate construct resulted in the lowest maximum moment at construct failure $(79 \pm 25 \mathrm{Nm})$ compared with the occipital anchor, which exhibited a mean peak moment of $90 \pm 31 \mathrm{Nm}(\mathrm{p}>0.05)$. The mechanisms and location of construct failure were consistent across treatment groups. Occipital anchors fractured through the slots that had been created for insertion (Fig. 6A). Specimens in the

TABLE 2. Multidirectional flexibility data: implant ROM

\begin{tabular}{|c|c|c|c|c|c|c|c|c|c|}
\hline \multirow[b]{3}{*}{ Loading Mode } & \multicolumn{3}{|c|}{ Occipital Plate-Screw $\left(^{\circ}\right)$} & \multirow{2}{*}{\multicolumn{2}{|c|}{$\begin{array}{c}\text { Intact } \\
\left({ }^{\circ}\right)\end{array}$}} & \multicolumn{4}{|c|}{ Occipital Anchor $\left({ }^{\circ}\right)$} \\
\hline & \multirow{2}{*}{$\begin{array}{l}\text { Intact } \\
\text { Plate }\end{array}$} & \multirow{2}{*}{$\begin{array}{l}\text { Prefatigue } \\
\text { Plate }\end{array}$} & \multirow{2}{*}{$\begin{array}{c}\text { Postfatigue } \\
\text { Plate }\end{array}$} & & & \multicolumn{2}{|c|}{ Prefatigue } & \multicolumn{2}{|c|}{ Postfatigue } \\
\hline & & & & Rt & $\mathrm{Lt}$ & $\mathrm{Rt}$ & $\mathrm{Lt}$ & $\mathrm{Rt}$ & $\mathrm{Lt}$ \\
\hline \multicolumn{10}{|l|}{ Flexion-extension } \\
\hline Mean & 0.20 & 0.06 & 0.13 & 0.09 & 0.08 & 0.10 & 0.11 & 0.18 & 0.17 \\
\hline SD & 0.14 & 0.05 & 0.06 & 0.08 & 0.09 & 0.08 & 0.17 & 0.12 & 0.24 \\
\hline \multicolumn{10}{|l|}{ Lateral bending } \\
\hline Mean & 0.04 & 0.54 & 0.62 & 0.02 & 0.03 & 0.24 & 0.28 & 0.37 & 0.33 \\
\hline SD & 0.03 & 0.30 & 0.34 & 0.02 & 0.02 & 0.08 & 0.19 & 0.17 & 0.13 \\
\hline \multicolumn{10}{|l|}{ Axial rotation } \\
\hline Mean & 0.05 & 0.11 & 0.13 & 0.06 & 0.08 & 0.06 & 0.16 & 0.17 & 0.20 \\
\hline SD & 0.04 & 0.07 & 0.14 & 0.04 & 0.05 & 0.05 & 0.17 & 0.26 & 0.20 \\
\hline
\end{tabular}




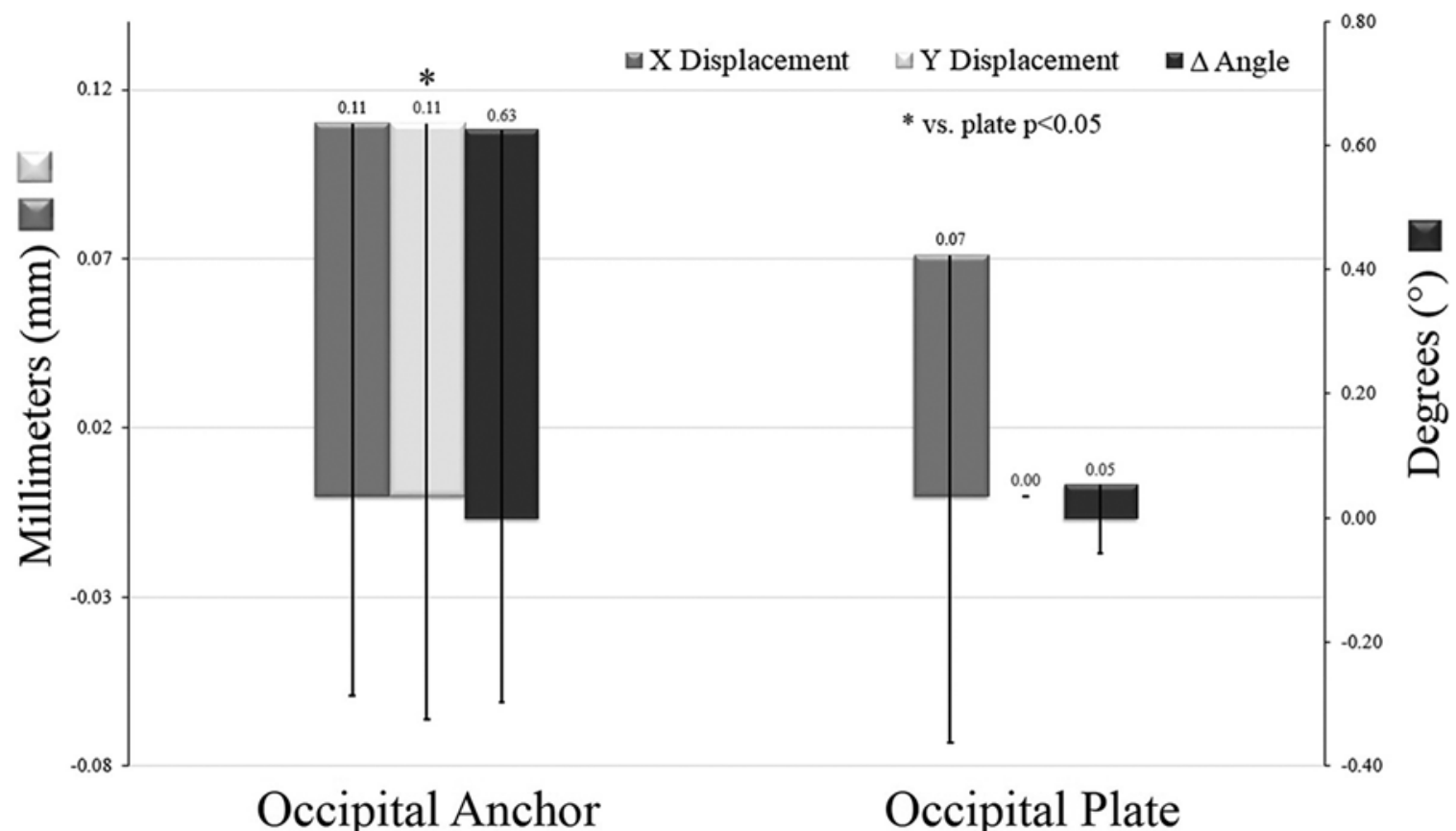

FIG. 5. Comparison of the overall change in angular rotation and $x$ - and $y$-axis displacement for the occipital anchors versus occipital plates. There were no significant differences between the occipital anchor and plate treatments in terms of angular rotation (degrees; $p=0.150)$ or $x$-axis displacement $(\mathrm{mm} ; p=0.572)$ based on quantitative analysis of the pre-and postfatigue fluoroscopic images $(p>0.05)$. There was a statistically significant difference in terms of $y$-axis displacement $(p=0.031)$. Bars indicate mean values and error bars minus 1 standard deviation.

occipital plate group failed with plate bending at the lateral occipital region and not at the point of the bone-screw interface (Fig. 6B). In all cases, the lateral mass screws and rod failed prior to the point of occipital fixation.

\section{Discussion}

The current study investigated the multidirectional flexibility and fixation properties of the occipital anchor-bolt as a surgical alternative to conventional plate-screw fixation for stabilization of the occipitocervical junction. There were no significant differences in multidirectional flexibility properties between the occipital anchor-bolt versus conventional plate-screw fixation following pre- or postfatigue loading conditions. More importantly, there was no biomechanical evidence of an increase in implant motion secondary to the fatigue loading component for either the plate or anchor device. Despite the biomechanically challenging loading condition and differences in BMD between the midline keel and lateral squamous regions of the occiput, the anchors and plates remained well positioned at the original implantation site and demonstrated no gross histological evidence of occipital fracture, implant migration, or osseous disruption under nondestructive loading conditions. These aforementioned findings provide biomechanical support for the occipital anchor-bolt as a viable surgical alterative for occipital fixation compared with conventional plate-screw constructs for stabilization of the occipitocervical junction.

The surface of the suboccipital region is variable be- tween patients in terms of osseous ridges and slopes, creating a challenge for implant-interface fixation. ${ }^{19}$ Despite this variability, both the occipital plate and anchors demonstrated no evidence of occipital fracture or osseous migration. A novel aspect of the current investigation was the ability to track the motion of an occipital implant, and thereby evaluate positional stability, based on quantitative fluoroscopic imaging. The anchor uses a compression-fit mechanism to attach to the occipital bone, and therefore it would be expected that lower bone density, variability in slot sizes, and inner table locking arrangements would predispose the interconnection mechanisms to motion. Furthermore, drilling of the slots reduces osseous support surrounding the implant and this, along with the slot direction, increases the implant's segmental motion with lateral bending as demonstrated. Although this was statistically significant, the results with ROM on the order of $0.3^{\circ}$ are likely not clinically significant. Collectively, these aforementioned differences in interconnection mechanisms and anatomical variability account for the observed increase in $y$-axis positional motion for the anchor system. Importantly, although significant, the y-axis motion quantified was on the order of $0.11 \mathrm{~mm}$ (110 microns) and is likely not of clinical relevance concerning instrumentation failure or migration. The senior author (F.A.S.) has performed 32 occipitocervical fusions using this occipital anchor-bolt technique over the last 4 years with an average follow-up of 33.3 months (range 13-52 months) without incidence of instrumentation complications. or pseudarthrosis necessitating revision (Fig. 7). Two isolated screw lucencies at the 

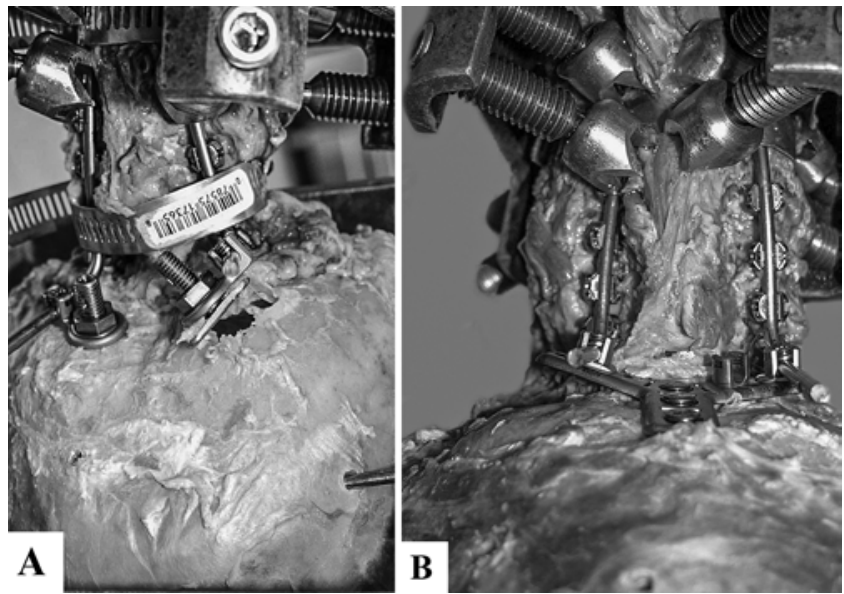

FIG. 6. Destructive testing-failure mechanism. A: Posterior view of an occipital anchor construct that failed through direct pullout of the occipital anchor through the trough. B: Posterior view of an occipital plate construct that failed by bending of the lateral plate. In both reconstructions a circumferential stainless-steel band was applied at C1-2 to augment fixation of the rod and lateral mass screws to distribute the applied moment directly to the point of occipital fixation.

caudal (C2) screw have been noted on follow-up imaging, absent of pseudarthrosis or clinical symptomology. The primary patient population for the senior author included patients with Ehlers-Danlos syndrome. The use of occipital fixation can be clinically utilized in patients with a suboccipital craniectomy, trauma, or tumor or as a salvage procedure in cases in which an occipital plate fixation is not technically possible.

An understanding of the anatomy of the cranial base, or suboccipital region, is critical to identifying safe fixation points. The occipitocervical junction consists of the base of the occipital bone, atlas, and axis. The thickness of the occiput is greatest in the midline and decreases in a radial fashion, moving laterally and inferiorly from the inion. ${ }^{19,20}$ The critical anatomy and mobility of the region pose a biomechanical challenge to various construct designs. Constructs must interface with the complex osseous terrain until arthrodesis has been achieved. It is also suggested that lateral screw placement on the occiput can improve the effective moment arm for lateral forces. Drilling the slot is an important technical consideration for occipital anchor insertion and familiarity with the suboccipital region will improve comfort with drilling. The occipital slot created during the current investigation was angled medially, from superior to inferior, as is performed clinically. The anchors were positioned at a $90^{\circ}$ angle to the slot axis, which appeared to optimize the instrumentation conformity along the contours of the inner occipital cortex. This slot becomes useful to facilitate rod placement as the construct is connected to the caudal cervical screws. The diameter of the slot should not exceed $10 \mathrm{~mm}$ in width because this will reduce the ability of the anchor to rigidly engage the inner table of the cranium. Care must be taken to limit insertional compression of the anchors to minimize the risk of cerebellar contusion and CSF leak. Compared to lateral points of fixation, the midline occipital

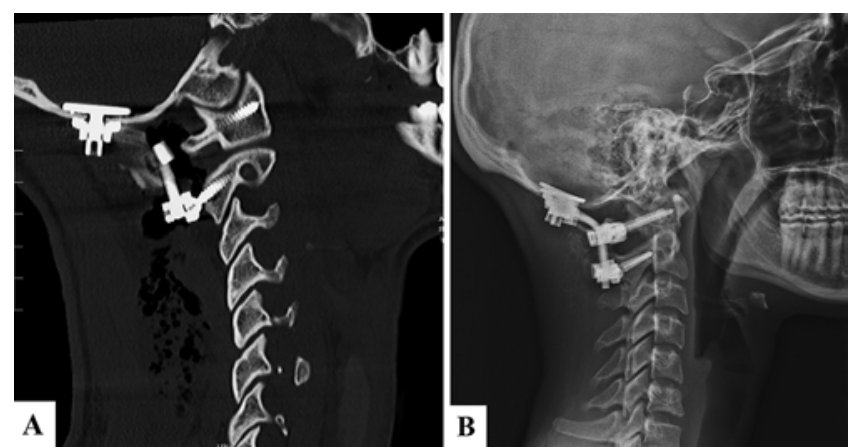

FIG. 7. Clinical case presentation of a 26 -year-old woman with EhlersDanlos syndrome who developed clival axial instability requiring an occipitocervical fusion. Sagittal CT of the cervical spine (A) demonstrates the low-profile nature of the occipital anchor as it compresses the occipital bone. Also observed are the spikes located on the inside plate that secure the implant into the bone. Lateral cervical spine radiographs (B) show the entire construct from the occiput to $\mathrm{C} 2$. The patient is now 15 months postoperative without evidence of instrumentation complications.

screw-plate technique poses less risk of cerebellar injury and CSF leak due to the dense bone mass of the keel. The dural sinuses and keel are relevant anatomical structures that impact fixation. The surgeon should be comfortable estimating the location and path of the dural sinuses based on external bone landmarks in an effort to minimize risk with instrumentation placement. Additionally, review of the thickness of the keel is an important factor in determining screw length.

Limitations of the current study include variability in cadaveric tissue age, size, and BMD, which may account for the lack of statistically significant differences in some comparisons. Furthermore, the present investigation utilized pure moment loading application without application of an axial compressive follower load. Differences in occipitocervical joint motion might have been greater if a compressive load had been incorporated.

\section{Conclusions}

The current study highlights the biomechanical similarity of using an occipital anchor technique as an alternative to traditional plate-screw fixation techniques for stabilization of the occipitocervical junction. From a biomechanical standpoint, the occipital anchor technique offered similar reductions in ROM despite a compression-fit mechanism to provide fixation in a less dense region of the occiput. Moreover, flexural load to failure did not differ significantly between the lateral squamous and midline keel regions, which highlights the osseous integrity of lateral fixation in the occipital region. The current investigation provides a biomechanical basis for the use of an occipital anchor technique as a viable clinical alternative to an occipital plate.

\section{Acknowledgments}

We thank Lyn Camire, MA, ELS, of the MedStar Health Research Institute, MedStar Union Memorial Hospital, for editorial assistance. 


\section{References}

1. Lopez AJ, Scheer JK, Leibl KE, et al. Anatomy and biomechanics of the craniovertebral junction. Neurosurg Focus. 2015;38(4):E2.

2. White AA III, Panjabi MM. The clinical biomechanics of the occipitoatlantoaxial complex. Orthop Clin North Am. 1978;9(4):867-878.

3. Newman P, Sweetnam R. Occipito-cervical fusion. An operative technique and its indications. J Bone Joint Surg Br. 1969;51(3):423-431.

4. Perry J, Nickel VL. Total cervical-spine fusion for neck paralysis. J Bone Joint Surg Am. 1959;41-A(1):37-60.

5. Apostolides PJ, Dickman CA, Golfinos JG, et al. Threaded Steinmann pin fusion of the craniovertebral junction. Spine (Phila Pa 1976). 1996;21(14):1630-1637.

6. Cohen MW, Drummond DS, Flynn JM, et al. A technique of occipitocervical arthrodesis in children using autologous rib grafts. Spine (Phila Pa 1976). 2001;26(7):825-829.

7. Abumi K, Takada T, Shono Y, et al. Posterior occipitocervical reconstruction using cervical pedicle screws and plate-rod systems. Spine (Phila Pa 1976). 1999;24(14):1425-1434.

8. Akbay A, Isikay I, Orunoglu M. Occipitocervical fixation using occipital bone hooks and cervical lateral mass screws: analysis of 16 cases. Turk Neurosurg. 2014;24(4):558-564.

9. Anderson PA, Oza AL, Puschak TJ, Sasso R. Biomechanics of occipitocervical fixation. Spine (Phila Pa 1976). 2006;31(7):755-761.

10. Haher TR, Bergman M, O'Brien M, et al. The effect of the three columns of the spine on the instantaneous axis of rotation in flexion and extension. Spine (Phila Pa 1976). 1991;16(8)(suppl):S312-S318.

11. Hurlbert RJ, Crawford NR, Choi WG, Dickman CA. A biomechanical evaluation of occipitocervical instrumentation: screw compared with wire fixation. J Neurosurg. 1999;90(1) (suppl):84-90.

12. Oda I, Abumi K, Sell LC, et al. Biomechanical evaluation of five different occipito-atlanto-axial fixation techniques. Spine (Phila Pa 1976). 1999;24(22):2377-2382.

13. Oda I, Cunningham BW, Lee GA, et al. Biomechanical properties of anterior thoracolumbar multisegmental fixation: an analysis of construct stiffness and screw-rod strain. Spine (Phila Pa 1976). 2000;25(18):2303-2311.

14. Vender JR, Rekito AJ, Harrison SJ, McDonnell DE. The evolution of posterior cervical and occipitocervical fusion and instrumentation. Neurosurg Focus. 2004;16(1):E9.
15. Felbaum D, Spitz S, Sandhu FA. Correction of clivoaxial angle deformity in the setting of suboccipital craniectomy: technical note. J Neurosurg Spine. 2015;23(1):8-15.

16. Pait TG, Al-Mefty O, Boop FA, et al. Inside-outside technique for posterior occipitocervical spine instrumentation and stabilization: preliminary results. J Neurosurg. 1999;90(1)(suppl):1-7.

17. Sandhu FA, Pait TG, Benzel E, Henderson FC. Occipitocervical fusion for rheumatoid arthritis using the insideoutside stabilization technique. Spine (Phila Pa 1976). 2003;28(4):414-419.

18. Panjabi MM. Biomechanical evaluation of spinal fixation devices: I. A conceptual framework. Spine (Phila Pa 1976). 1988;13(10):1129-1134.

19. Zipnick RI, Merola AA, Gorup J, et al. Occipital morphology. An anatomic guide to internal fixation. Spine (Phila Pa 1976). 1996;21(15):1719-1724, 1729-1730.

20. Ebraheim NA, Lu J, Biyani A, et al. An anatomic study of the thickness of the occipital bone. Implications for occipitocervical instrumentation. Spine (Phila Pa 1976). 1996;21(15):1725-1730.

\section{Disclosures}

Research funding for the study was provided by Stryker Spine, Inc. Dr. Sandhu reports receiving royalties from Stryker Spine.

\section{Author Contributions}

Conception and design: Cunningham, Mullinix. Acquisition of data: Cunningham, Mullinix, Sun. Analysis and interpretation of data: Cunningham, Mueller. Drafting the article: Cunningham, Mueller. Critically revising the article: all authors. Reviewed submitted version of manuscript: all authors. Approved the final version of the manuscript on behalf of all authors: Cunningham. Statistical analysis: Cunningham. Administrative/technical/material support: Cunningham, Mullinix, Sun, Sandhu. Study supervision: Cunningham, Sandhu.

\section{Correspondence}

Bryan W. Cunningham: Musculoskeletal Research Center, MedStar Union Memorial Hospital, Baltimore, MD. bcspine@ gmail.com. 